\title{
Health-Related Quality of Life of Children and Adolescents with Growth Hormone Deficiency or Idiopathic Short Stature - Part 2: Available Results and Future Directions
}

\author{
Monika Bullinger ${ }^{\mathrm{a}}$ Maria Kołtowska-Häggström ${ }^{c, d}$ David Sandberg ${ }^{g}$ \\ John Chaplin ${ }^{\mathrm{e}}{ }^{f}$ Hartmut Wollmann ${ }^{\text {h }}$ Meinolf Noeker ${ }^{b}$ Anna Levke Brütt ${ }^{a}$

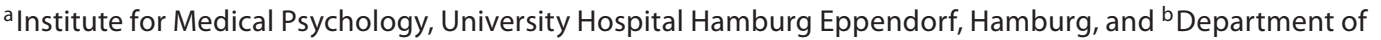 \\ Pediatrics, University of Bonn, Bonn, Germany; ${ }^{C}$ KIMS Medical Outcomes, Pfizer Endocrine Care, Sollentuna, \\ ${ }^{\mathrm{d}}$ Department of Pharmacy, Uppsala University, Uppsala, ${ }^{\mathrm{e}}$ Gothenburg Pediatric Growth Research Center, and \\ fDepartment of Pediatrics, The Queen Silvia Children's Hospital, Växthuset, Gothenburg, Sweden; \\ ${ }^{9}$ Department of Pediatrics and Communicable Diseases, Division of Child Behavioral Health, University of

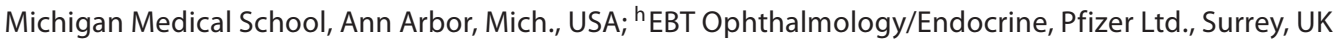

\section{Key Words}

Growth hormone deficiency · Idiopathic short stature •

Quality of life

\section{Abstract}

Research on the health-related quality of life (HrQoL) impact of short stature and its treatment in children and adolescents has developed recently. Based on a PubMed literature search, studies addressing this issue were identified and considerable methodological problems mainly related to the HrQoL instruments used and conflicting results are discussed in this mini review. Additionally, this mini review identifies a need for further research and indicates potential directions.

Copyright $\odot 2009$ S. Karger AG, Basel

\section{Introduction}

Short stature (SS) is a relative concept. It is conventionally defined as a height of two standard deviations (SDs) or more below the mean, or approximately the 3rd per-

\section{KARGER}

Fax +4161306 1234

E-Mail karger@karger.ch

www.karger.com
(C) 2009 S. Karger AG, Basel

0301-0163/09/0722-0074\$26.00/0

Accessible online at:

www.karger.com/hre centile [1]. Each year, 90,000 children are born in the USA with a height that, by definition, falls below the 2nd percentile and thereby are considered to have SS. If the less rigid 5th percentile cutoff is used, as is frequently the case in clinical practice, then 150,000 children a year would be classified as having SS, assuming a normal distribution for heights in the general population [2]. SS in children may have different causes, including normal variation, genetic defects, malnutrition, chronic systemic disease, endocrine disorders or psychosocial deprivation. Growth hormone deficiency (GHD) represents a relatively rare cause for $\mathrm{SS}$, which is due to insufficient secretion of growth hormone (GH). However, most youths with SS are GH sufficient based on laboratory tests [3]. The heterogeneous group whose SS is not attributable to underlying pathology is classified as idiopathic short stature (ISS). Definition of ISS involves a height $\leq-2$ SDs for age and sex and the exclusion of systemic disease $[4,5]$.

Conflict of Interest Statement: D.S. was a consultant to Pfizer Inc.; H.W. and M.K.-H. are Pfizer employees. 
GH therapy is the most effective treatment option to increase growth velocity and adult height in persons with GHD. In many countries, GH is an approved treatment not only for children with GHD, but also for Turner syndrome, renal failure, children born small for gestational age, and Prader-Willi syndrome. Children with ISS exhibit increased growth with GH treatment $[4,6]$ and the US Food and Drug Administration approved this indication in 2003. Results of GH studies in ISS show an average gain in adult height of approximately $4-6 \mathrm{~cm}$ [4]. In a recent Cochrane Review, Bryant et al. [7] concluded that GH therapy in ISS can increase short-term growth and adult height. However, patients remain relatively short compared to peers.

Since it is not yet clear which benefits are associated with GH treatment, and specifically if GH-induced height gain is associated with changes in health-related quality of life (HrQoL), research should address these HrQoL outcomes, especially focusing on measures that can be used in economic modeling $[7,8]$. Interest in HrQoL, as an indicator of patient-reported health outcomes and benefits, has extended to pediatric populations, and studies are available, especially in the area of chronic disease in children and adolescents. In children with SS, psychological research has focused on functioning and performance rather than on well-being and adaptation.

Studies of impairments associated with SS do not often specifically address ISS, but are often confounded with conditions in which SS is a feature of a phenotype specific to a particular medical condition or syndrome. In a review limited to children with SS (as the major diagnosis), Wheeler et al. [9] concluded that short children scored lower than their peers on intelligence tests, academic achievement and behavioral adaptation, but the scores fell within the normative range (1 SD). Deficits for youths with SS were reported in visual-motor skills as well as psychological, educational and behavioral functioning [9]. Nonetheless, it remains unclear whether the deficits are the consequence of an underlying condition causing SS, or cognitive and psychological sequelae. Taking into account other studies on SS and functional impairment, no direct link has been found [10, 11].

Psychosocial effects of SS have been reported to include stigmatization and social isolation due to staturerelated stereotypes $[12,13]$. Some studies report that short children experience chronic psychosocial stress [14, 15], although these experiences do not generally result in clinically significant problems of psychosocial adaptation $[13,10]$.

HrQoL of Children and Adolescents with GHD or ISS
Table 1. Literature search for articles in the PubMed database

\begin{tabular}{lrr}
\hline & ISS & GHD \\
\hline Quality of life & & \\
$\quad$ All & 13 & 236 \\
$\quad$ Children & 12 & 72 \\
Preferences & 0 & 1 \\
Patient satisfaction & & \\
$\quad$ All & 2 & 4 \\
Children & 1 & 2 \\
\hline
\end{tabular}

The recent literature is inconclusive with regard to whether or not SS, per se, is a handicapping condition. Furthermore, emotional problems secondary to teasing or low self-esteem have not been unequivocally confirmed $[15,16]$. According to parent reports, short children exhibit lower social competencies and more problems in social interaction than children with stature within the normative range [17]. Other studies, however, have failed to detect deficits in academic or psychosocial functioning among children with SS [10, 18].

Risk factors potentially affecting psychosocial adaptation among those with SS include male gender, the presence of a younger but taller sibling, being perceived and treated as younger than chronological age, lower intelligence, and lower family socioeconomic status [17]. As many of these constitute 'risk factors' for children with average stature, they are not specific for those with SS.

Thus it remains unclear why some children with SS develop psychologically well and others do not $[19,20]$.

\section{HrQoL Research in Children and Adolescents with ISS and GHD Studies of QoL, Patient Preferences and Patient Satisfaction}

If $\mathrm{HrQoL}$ is thought to be an important consideration in treatment decisions for children with ISS, studies including validated $\mathrm{HrQ}$ oL measures are needed. However, such studies are rare at this time $[11,21]$. A review of studies examining the influence of SS and GH treatment reveals that investigations have not systematically analyzed findings separately for GHD and ISS (previous article).

A PubMed literature search resulted in only 13 articles using the key words 'idiopathic short stature' and 'quality of life'. Even fewer articles were found when combining ISS with the terms 'preferences' ( 0 ) or 'patient satisfaction' (2). Limiting the search to 'growth hormone defi-

Horm Res 2009;72:74-81 
Table 2. Studies assessing HrQoL in children and adolescents with SS

\begin{tabular}{|c|c|c|c|c|c|c|}
\hline Study & Instrument & Respondent & $\begin{array}{l}\text { Sample } \\
\text { size }\end{array}$ & Sample & Sample source & Age \\
\hline \multicolumn{7}{|c|}{ QoL in patients with growth disorders (including GHD and ISS) } \\
\hline $\begin{array}{l}\text { Leiberman et al. } \\
{[22]}\end{array}$ & QoL & children & $\mathrm{n}=96$ & $\begin{array}{l}\text { GH treatment } \\
\text { GHD: } 15\end{array}$ & hospital setting & $8-16$ years \\
\hline $\begin{array}{l}\text { Pilpel et al. } \\
\text { [23] }\end{array}$ & & & & $\begin{array}{l}\text { ISS: } 65 \text {; TS: } 16 \\
\text { not treated: } 33\end{array}$ & & \\
\hline $\begin{array}{l}\text { Sandberg et al. } \\
\text { [24] }\end{array}$ & CBCL & parent & $\mathrm{n}=258$ & SS & hospital setting & $4-18$ years \\
\hline $\begin{array}{l}\text { Cramer et al. } \\
{[25]}\end{array}$ & VSP-AM & children & $\mathrm{n}=172$ & $\begin{array}{l}\text { GHD: 125; ISS: 19; TS: } 17 \\
\text { unknown: } 11\end{array}$ & GH treatment & $11-19$ years \\
\hline $\begin{array}{l}\text { Norrby et al. } \\
{[26]}\end{array}$ & CHQ & child, parent & $\mathrm{n}=51$ & SS & hospital setting & $9-16$ years \\
\hline \multicolumn{7}{|c|}{ Studies on GH treatment in ISS patients } \\
\hline $\begin{array}{l}\text { Theunissen et al. } \\
\text { [30] }\end{array}$ & $\begin{array}{l}\text { TNO-AZL } \\
\text { TACQOL } \\
\text { ISSQOL } \\
\text { DUCATQO } \\
\text { L }\end{array}$ & parent, child & $\mathrm{n}=36$ & $\begin{array}{l}\text { ISS; GH treatment: } 20 \\
\text { control: } 20\end{array}$ & $\begin{array}{l}\text { randomized } \\
\text { clinical trial }\end{array}$ & $\begin{array}{l}4-10 \text { years } \\
\text { (at start) }\end{array}$ \\
\hline \multirow[t]{2}{*}{$\begin{array}{l}\text { Ross et al. } \\
{[27]}\end{array}$} & CBCL & parent & $\mathrm{n}=59$ & $\begin{array}{l}\text { ISS; GH treatment: } 33 \\
\text { placebo: } 26\end{array}$ & clinical setting & $9-16$ years \\
\hline & SPP & child & $\mathrm{n}=59$ & $\begin{array}{l}\text { ISS; GH treatment: } 32 \\
\text { placebo: } 27\end{array}$ & & \\
\hline \multicolumn{7}{|c|}{ Studies on GH treatment in GHD patients } \\
\hline $\begin{array}{l}\text { Attanasio et al. } \\
\text { [35] }\end{array}$ & QLS-H & adolescents & $\mathrm{n}=66$ & $\begin{array}{l}\text { GHD } \\
\text { GH treatment pediatric dose: } 25 \\
\text { GH treatment adult dose: } 28 \\
\text { not treated: } 13\end{array}$ & hospital setting & $14-24$ \\
\hline $\begin{array}{l}\text { Mauras et al. } \\
{[32]}\end{array}$ & QoL-AGDHA & adolescents & $\mathrm{n}=55$ & $\begin{array}{l}\text { GHD; GH treatment: } 25 \\
\text { placebo: } 15 \text {; control: } 15\end{array}$ & hospital setting & mean: 15.8 \\
\hline $\begin{array}{l}\text { Sheppard et al. } \\
\text { [31] }\end{array}$ & PedsQL & $\begin{array}{l}\text { parent, } \\
\text { children }\end{array}$ & $\mathrm{n}=22$ & $\begin{array}{l}\text { GHD; acquired GHD: } 14 \\
\text { idiopathic GHD: } 8\end{array}$ & clinical setting & $8-16$ years \\
\hline $\begin{array}{l}\text { Lagrou et al. } \\
\text { [37] }\end{array}$ & QoL-AGDHA & $\begin{array}{l}\text { adult } \\
\text { (retrospective) }\end{array}$ & $\mathrm{n}=36$ & $\begin{array}{l}\text { GHD; isolated GHD: } 26 \\
\text { multiple GHD: } 10\end{array}$ & clinical setting & mean: 20.0 \\
\hline \multicolumn{4}{|c|}{$\begin{array}{l}\text { C = Children; P = parents; CBCL = Child Behavior Checklist } \\
\text { [44]; VSP-AM = Vecú et Santé Perçue de l'Adolescent [45]; } \\
\text { CHQ = Child Health Questionnaire [46]; ISSQOL = Idiopathic } \\
\text { Short Stature QoL Questionnaire; TACQOL = TNO AZL Chil- } \\
\text { dren's Quality of Life [47]; DucatQoL = Dutch Children's AZL/ }\end{array}$} & \multicolumn{3}{|c|}{$\begin{array}{l}\text { TNO Quality of Life Questionnaire [48]; SSP = Self-Perception } \\
\text { Profile [49]; QLS-H = Questions on Life Satisfaction-Hypopitu- } \\
\text { itarism [36]; QoL-AGHDA = Quality of Life-Assessment of } \\
\text { Growth Hormone Deficiency in Adults [34]; PedsQoL = Pediatric } \\
\text { Quality of Life Inventory [50]. }\end{array}$} \\
\hline
\end{tabular}




\begin{tabular}{ll}
\hline Study aim & Results \\
\hline
\end{tabular}

\begin{tabular}{|c|c|}
\hline QoL and SS & $\begin{array}{l}\text { No differences with respect to gender, underlying disease or onset or } \\
\text { duration of treatment }\end{array}$ \\
\hline effects of treatment on QoL & No differences in QoL between GH-treated and nontreated groups \\
\hline QoL and SS & $\begin{array}{l}\text { Boys were less socially competent and had more behavioral and emotional } \\
\text { problems by parent report; boys rated themselves as less socially active, all } \\
\text { other boys scores and girls score were within normative range }\end{array}$ \\
\hline psychometric testing & $\begin{array}{l}\text { Better VSP-AM QoL scores for all subscales and total except for self } \\
\text { esteem compared to medical, surgical or psychiatric comparison groups }\end{array}$ \\
\hline psychometric testing & $\begin{array}{l}\text { Highest QoL in SS compared to juvenile chronic arthritis, diabetes and } \\
\text { asthma, expect self-esteem }(\mathrm{C}, \mathrm{P}) \text { and behavior }(\mathrm{P})\end{array}$ \\
\hline QoL effects of GH therapy & $\begin{array}{l}\text { HrQoL comparable to population, except lower scores in social } \\
\text { functioning }(C, P) \text {, no improvement of HrQoL during treatment }\end{array}$ \\
\hline \multirow[t]{2}{*}{ QoL effects of GH therapy } & $\begin{array}{l}\text { Behavioral scores comparable to population norms at baseline; differences } \\
\text { between treatment and control group observed in year } 4 \text { after substantial } \\
\text { participant dropout }\end{array}$ \\
\hline & $\begin{array}{l}\text { Baseline scores within normal range, and no subsequent differences } \\
\text { between groups }\end{array}$ \\
\hline QoL effects of GH therapy & $\begin{array}{l}\text { Baseline QoL scores in the lower normal range; differences were found in } \\
\text { ability to become sexually aroused, ability to tolerate stress, ability to } \\
\text { concentrate, self confidence, physical endurance and body shape and } \\
\text { appeared to respond positively to GH treatment }\end{array}$ \\
\hline QoL effects of GH therapy & $\begin{array}{l}\text { Normal HrQoL when reaching adult height, continuation of GH } \\
\text { replacement not associated with improvements relative to placebo or } \\
\text { control group }\end{array}$ \\
\hline QoL effects of GH therapy & $\begin{array}{l}\text { AGHD QoL below population norms and improved QoL over time; no } \\
\text { significant results for idiopathic GHD children }\end{array}$ \\
\hline $\begin{array}{l}\text { retrospective perception of } \\
\text { QoL effect of GH therapy }\end{array}$ & $\begin{array}{l}\text { Patients initiating GH treatment after the age of } 12 \text { complained about } \\
\text { difficulties in self-confidence, social contact and contact with the opposite } \\
\text { sex and emotional life }\end{array}$ \\
\hline
\end{tabular}


ciency' or 'GH deficiency' and 'quality of life', 236 articles were found, of which 72 concerned children. Additionally, four studies on 'patient satisfaction' were found and only one study on patient 'preferences' (table 1). Articles on GH treatment are more common, particularly those that focus on adult height attained [7]. Although the construct of HrQoL may have been mentioned in many of these studies, only a few adequately measured HrQoL; these are described in detail below (table 2). The key word search strategy employed in this mini review restricted studies to those specifically taking into account HrQoL. Studies of psychosocial adaptation or related constructs were not included in the search strategy.

\section{QoL in Patients with Growth Disorders (Including GHD and ISS)}

Leiberman et al. [22] were the first to assess patient satisfaction in GH-treated children with SS. They incorporated their own HrQoL questionnaire which included an assessment of coping and satisfaction with GH treatment. Ninety-six children (65 without underlying medical conditions, 15 with GHD and 16 with Turner syndrome) filled out the questionnaire during a regular endocrinology visit. Results revealed that patients tolerated treatment, coped well, and expressed satisfaction with treatment. Differences between patients with and without underlying medical conditions were not found. Additionally, a cross-sectional comparison of GH-treated patients with a nontreated control group did not detect differences in school achievements, leisure activities, emotional and physical self-esteem, relationships with peers or family members [23]. In another heterogeneous sample of 180 boys and 78 girls with growth disorders, boys were rated by a parent as less socially competent and exhibiting more behavioral and emotional problems than a normative sample. However, they were significantly more socially competent and showed fewer psychopathologic symptoms than a psychiatric-referred sample of comparable age. Girls in the same study were comparable to the normative group according to both parent and selfreport [24]. Similarly, Cramer et al. [25] reported a better QoL of patients with growth disorders (GHD: 125, ISS: 19, Turner Syndrome: 17, other related diagnoses: 9) compared to patients with medical, surgical or psychiatric disorders, except for the self-esteem domain. Another study of patients with SS reported higher HrQoL in physical function, bodily pain and general health perceptions compared to groups with chronic illness. Ratings on the dimensions of self-esteem and behavior did not differ from patients with asthma or diabetes [26].

\section{Studies of GH Treatment in ISS Patients}

Ross et al. [27] randomly assigned 68 children to receive either GH or placebo. A trend towards reduced behavior problem was observed in the treated group, but only by parent report and for the very limited subset of patients who remained in the study in its final (fourth) year $(\mathrm{GH}$-treated $n=9$; placebo $n=3)$. Effects of $\mathrm{GH}$ on parent-reported social competencies or participant ratings of self-concept were not observed.

Theunissen et al. [28] reported that children with ISS did not generally exhibit impairments in QoL measured by the TNO AZL Children's Quality of Life [29] self-report questionnaire, the social functioning domain being the exception. When comparing GH-treated and untreated children, pediatricians providing the care reported improved HrQoL in the treatment group; parent and child ratings, however, did not differ between treatment and control groups. Instead, perceived height and satisfaction with current height were associated with higher HrQoL ratings and self-esteem [28]. To date this is the only study in children with ISS which used a combination of generic (TNO AZL Children's Quality of Life) and condition-specific (Idiopathic Short Stature QoL [30]) measures.

\section{Studies of GH Treatment in GHD Patients}

Sheppard et al. [31] examined parents and self-reports of QoL among 14 children with idiopathic GHD and 8 with acquired GHD (following a malignancy and its treatment) before and after 6 months of GH treatment. Ratings for patients with acquired GHD were significantly below population norms before and improved with treatment, whereas the subgroup with idiopathic GHD did not show significant changes in QoL.

The transition from pediatric to adult health care is of special importance. Accordingly, the correspondence between measures and study results for children and adults is important to evaluate. In a study examining the metabolic and HrQoL benefits of GH during the transition to the adult phase of treatment in adolescents with GHD, Mauras et al. [32] employed both generic (Short Form 36 Health Survey [33]) and condition-specific (Quality of Life-Assessment of Growth Hormone Deficiency in Adults [34]) HrQoL measures in a double-blind, placebocontrolled study. At near completion of linear growth, and while still on treatment, mean HrQoL scores on the generic measure did not differentiate the GHD patients from general population norms. Furthermore, GH treatment over the subsequent 2 years was not associated with changes in generic or condition-specific HrQoL scores compared to the placebo control group. 
Studies in adolescents and young adults have also employed adult condition-specific questionnaires to measure HrQoL. In a multinational study examining the transition phase of GH treatment following attainment of adult height, Attanasio et al. [35] randomly assigned patients with childhood onset GHD to three groups: continuation of GH therapy at two different dosages and an untreated control group. Study participants completed the Questions on Life Satisfaction-Hypopituitarism [36] questionnaire at baseline and annually for 2 years. Mean total scores at baseline fell in the low-normal range for the general population. However, scores on individual subscale items (e.g. perceptions of body shape, physical endurance, and self-confidence) were significantly lower than norms. GH treatment, at either dose, was not associated with an improvement in Questions on Life Satisfaction-Hypopituitarism scores compared to the untreated control group, but a within-group improvement in scores from baseline to 2 years was observed for the GH-treated groups (dosage subgroups combined) on the items 'ability to become sexually aroused' and 'body shape', relative to the untreated control group.

Lagrou et al. [37] examined psychosocial and QoL outcomes following GH therapy in 36 young adult patients (18-23 years) with childhood onset GHD (including both isolated GHD and multiple pituitary hormone deficiency subgroups). Those patients who were shorter at the initiation of treatment reported lower HrQoL (Quality of Life-Assessment of Growth Hormone Deficiency in Adults) scores as young adults $(\mathrm{r}=-0.43)$. Further, those participants who had initiated hormone replacement after the age of 12 reported significantly more difficulties with self-confidence and social relations during a semistructured interview than those starting treatment at an earlier age. This same subgroup reported a significantly increased likelihood of rating the timing of their pubertal onset as 'too late'. The subset of patients with multiple pituitary hormone deficiencies $(\mathrm{n}=10)$ were described by self- and parent report as experiencing more problems in life adjustment during childhood and in the present compared to patients $(n=26)$ with isolated GHD. Despite attaining adult heights comparable to mid-parental height $(-0.5 \pm 0.9$ SDs), a substantial proportion of participants' parents (higher in the multiple pituitary hormone-deficient group) anticipated that their child would experience difficulties in finding a job, leaving home, and developing a stable romantic relationship.

Health utility measures such as the EQ5D or the HUI have not yet been used in pediatric populations.

\section{Discussion}

HrQoL is increasingly considered as a relevant outcome in ISS and GHD and an important endpoint in GH treatment. As this mini review has demonstrated, $\mathrm{HrQoL}$ in ISS/GHD has been the focus of studies only for a relatively short time.

\section{Generic and Condition-Specific HrQoL Assessment}

Generic assessment methods were most frequently adopted for use in both adult and pediatric samples. The literature review showed that HrQoL in youths with ISS or GHD was comparable to the general population [9, 12-14]. This is possibly because the measures commonly employed in such research were generic in nature and the impact of physical development on HrQoL may have been underestimated or not taken into consideration at all.

\section{Self- and Proxy Ratings}

The current mini review also highlighted the limited concordance between parent and child ratings. While parents of short children commonly report problems of cognitive development, personality, self-esteem or social relations, their children do so only sporadically. Although some studies assessed behavior and adaptation by both self- and proxy report $[26,38]$, the correlation between child- and parent-rated HrQoL has yet to be systematically examined.

Utilizing peers as a source of information about the child's psychosocial adaptation is another source of information deserving serious consideration. The problems purported to stem from SS are believed to be linked to negative social interactions in the peer group, and yet there exists only limited research that has directly examined peer relations among youths with SS $[39,40]$.

\section{Importance of Height}

A fundamental issue for pediatric outcome assessment in GHD and ISS is the importance of height to experienced $\mathrm{HrQoL}$, and the relation between measured height gained and changes in HrQoL. A child's or adolescent's satisfaction with his/her own height is influenced by social perceptions (e.g. parent expectations, peer stigma). Accordingly, as has been shown in pediatric psychology, HrQoL can be affected not only by treatment, but also by supporting positive psychological adaptation and through modification of aspects of the proximal social environment [41-43]. 


\section{Future Directions}

A challenge for further research is to unravel the relative contributions of height, perceived height, and psychosocial adaptation to QoL in children with SS. The ultimate aim of such investigation is to better understand what life is like for these children and to examine the impact of SS and its treatment on patient-reported well-being and functioning.

\section{Acknowledgment}

This literature review was supported by a grant to M.B. from Pfizer Inc.

\section{References}

1 Lifshitz F, Cervantes CD: Short stature; in Lifshitz F (ed): Pediatric Endocrinology, ed 3. New York, Dekker, 1996, pp 1-18.

$\checkmark 2$ Lantos J, Siegler M, Cuttler L: Ethical issues in growth hormone therapy. JAMA 1989; 261:1020-1024.

3 Lee MM: Idiopathic short stature. N Engl J Med 2006;354:2576-2582.

-4 Finkelstein BS, Imperiale TF, Speroff T, Marrero U, Radcliffe DJ, Cuttler L: Effect of growth hormone therapy on height in children with idiopathic short stature: a metaanalysis. Arch Pediatr Adolesc Med 2002 156:230-240.

5 Cohen P, Rogol AD, Deal CL, Saenger P, Reiter EO, Ross JL, Chernausek SD, Savage MO, Wit JM; on behalf of the 2007 ISS Consensus Workshop participants: Consensus statement on the diagnosis and treatment of children with idiopathic short stature: a summary of the Growth Hormone Research Society, the Lawson Wilkins Pediatric Endocrine Society, and the European Society for Paediatric Endocrinology Workshop. J Clin Endocrinol Metab 2008;93:4210-4217.

6 Miller BS, Zimmerman D: Idiopathic short stature in children. Pediatr Ann 2004;33: 177-181.

7 Bryant J, Baxter L, Cave C, Milne R: Recombinant growth hormone for idiopathic short stature in children and adolescents. Cochrane Database Syst Rev 2007;3: CD004440.

8 Sandberg DE: Health-related quality of life as a primary endpoint for growth hormone therapy. Horm Res 2006;65:250-252.

9 Wheeler PG, Bresnahan K, Shephard BA, Lau J, Balk EM: Short stature and functional impairment. Arch Pediatr Adolesc Med 2004;158:236-243.

10 Kranzler JH, Rosenbloom A, Proctor B, Diamon $\mathrm{FB}$, Watson $\mathrm{M}$ : Is short stature a handicap? A comparison of the psychosocial functioning of referred and nonreferred children with normal short stature and with normal stature. J Pediatr 2000; 136:96-102.
11 Chaplin JE, Dahlgren J, Kriström B, Albertsson-Wikland A: Psychological importance to the child of growth hormone replacement; in Nyberg FJ (ed): The Somatotrophic Axis in Brain Function. Amsterdam, Elsevier, 2006, pp 249-266.

12 Voss LD, Mulligan J: Bullying in school: are short pupils at risk? Questionnaire study in a cohort. BMJ 2000;320:612-613.

13 Sandberg DE, Colsman M: Growth hormone treatment of short stature: status of the quality of life rationale. Horm Res 2005;63:275283.

14 Sandberg DE, MacGillivray MH, Clopper RR, Fung C, LeRoux L, Alliger DE: Quality of life among formerly treated childhoodonset growth hormone-deficient adults: a comparison with unaffected siblings. J Clin Endocrinol Metab 1998;83:1134-1142.

15 Zimet GD, Cutler M, Litvene M, Dahms W, Owens R, Cuttler L: Psychological adjustment of children evaluated for short stature: a preliminary report. J Dev Behav Pediatr 1995;16:264-270.

16 Sandberg DE: Quality of life and self-esteem in children treated for idiopathic short stature. J Pediatr 2003;143:691.

17 Visser-van Balen H, Sinnema G, Geenen R: Growing up with idiopathic short stature: psychosocial development and hormone treatment: a critical review. Arch Dis Child 2006;91:433-439.

18 Sandberg DE, Colsman MD, Voss LD: Short Stature and Quality of Life: A Review of Assumptions and Evidence, Pediatric Endocrinology: Mechanisms, Manifestations, and Management. Philadelphia, Lippincourt, Williams \& Wilkins, 2004, pp 191-202.

19 Noeker M, Haverkamp F: Adjustment in conditions with short stature: a conceptual framework. J Pediatr Endocrinol Metab 2000;13:1585-1594.

20 Erling A: Why do some children of short stature develop psychologically well while others have problems? Eur J Endocrinol 2004;151:35-39.

21 Radcliffe DJ, Pliskin JS, Silvers JB, Cuttler L: Growth hormone therapy and quality of life in adults and children. Pharmacoeconomics 2004;22:499-524.
22 Leiberman E, Pilpel D, Carel CA, Levi E, Zadik Z: Coping and satisfaction with growth hormone treatment among short-stature children. Horm Res 1993;40:128-135.

-23 Pilpel D, Leiberman E, Zadik Z, Carel CA Effect of growth hormone treatment on quality of life of short-stature children. Horm Res 1995;44:1-5.

24 Sandberg DE, Brook AE, Campos SP: Short stature: a psychosocial burden requiring growth hormone therapy? Pediatrics 1994; 94:832-840.

25 Cramer JA, Claude Simeoni M, Auquier P, Robitail S, Brasseur P, Beresniak A: Brief report: a quality of life instrument for adolescents with growth disorders. J Adolesc 2005; 28:595-600.

26 Norrby U, Nordholm L, Andersson-Gäre B, Fasth A: Health-related quality of life in children diagnosed with asthma, diabetes, juvenile chronic arthritis or short stature. Acta Paediatr 2006;95:450-456.

-27 Ross JL, Sandberg DE, Rose SR, Leschek EW, Baron J, Chipman JJ, Cassorla FG, Quigley CA, Crowe BJ, Roberts K, Culter GH: Psychological adaptation in children with idiopathic short stature treated with growth hormone or placebo. J Clin Endocrinol Metab 2004;89:4873-4878.

28 Theunissen NC, Kamp GA, Koopman HM, Zwinderman KA, Vogels T, Wit JM: Quality of life and self-esteem in children treated for idiopathic short stature. J Pediatr 2002;140: 507-515.

- 29 Verrips GH, Vogels AGC, Koopman HM, Theunissen NCM, Kamphuis RP, Wit HM, Verloove Vanhorick SP: Measuring healthrelated quality of life in a child population. Eur J Public Health 1999;9:188-193.

30 Theunissen NC, Kamp GA, Koopman HM, Zwinderman KA, Vogels T, Wit JM: Quality of life and self-esteem in children treated for idiopathic short stature. J Pediatr 2002;140: 507-515.

- 31 Sheppard L, Eiser C, Davies HA, Carney S, Clarke SA, Urquart T, Ryder MJ, Stoner A, Wright NP, Butler G: The effects of growth hormone treatment on health-related quality of life in children. Horm Res 2006;65:243249. 
-32 Mauras N, Pescovitz OH, Allada V, Messig M, Wajnrajch MP, Lippe B; Transition Study Group: Limited efficacy of growth hormone (GH) during transition of $\mathrm{GH}$-deficient patients from adolescence to adulthood: a phase III multicenter, double-blind, randomized two-year trial. J Clin Endocrinol Metab 2005;90:3946-3955.

33 Ware JE Jr, Sherbourne CD: The MOS 36item short-form health survey (SF-36). Conceptual framework and item selection. Med Care 1992;30:473-483.

34 McKenna SP, Doward LC, Alonso J, Kohlmann T, Niero M, Prieto L, Wiren L: The QoL-AGHDA: an instrument for the assessment of quality of life in adults with growth hormone deficiency. Qual Life Res 1999;8: 373-383.

35 Attanasio AF, Shavrikova EP, Blum WF, Shalet SM: Quality of life in childhood onset growth hormone-deficient patients in the transition phase from childhood to adulthood. J Clin Endocrinol Metab 2005;90: 4525-4529.

36 Herschbach P, Henrich G, Strasburger CJ, Feldmeier H, Marin F, Attanasio AM, Blum WF: Development and psychometric properties of a disease-specific quality of life questionnaire for adult patients with growth hormone deficiency. Eur J Endocrinol 2001; 145:255-265.
- 37 Lagrou K, Xhrouet-Heinrichs D, Massa G, Vandeweghe M, Bourguignon JP, De Schepper J, de Zegher F, Ernould C, Heinrichs C, Malvaux P, Craen M: Quality of life and retrospective perception of the effect of growth hormone treatment in adult patients with childhood growth hormone deficiency. J Pediatr Endocrinol Metab 2001;14(suppl 5):1249-1260.

38 Sandberg DE, Ognibene TC, Brook AE, Barrick C, Shine B, Grundher W: Academic outcomes among children and adolescents receiving growth hormone therapy. Child Health Care 1998;27:265-282.

39 Gilmour J, Skuse D: Short stature - the role of intelligence in psychosocial adjustment. Arch Dis Child 1996;75:25-31.

40 Sandberg DE, Bukowski WM, Fung CM, Noll RB: Height and social adjustment; are extremes a cause for concern and action? Pediatrics 2004;114:744-750.

41 Perrin JM: Health services research for children with disabilities. Milbank Q 2002;80: 303-324.

42 Clarke S, Eiser C: The measurement of health-related quality of life (QoL) in paediatric clinical trials: a systematic review. Health Qual Life Outcomes 2004;2:66.

43 Petersen C, Schmidt S, Bullinger M; DISABKIDS Group: Coping with a chronic pediatric health condition and health-related quality of life. Eur Psychol 2006;11:50-56.
44 Achenbach TM: Program Manual for the Child Behavior Checklist and Revised Child Behavior/4-18 Profile. Burlington, Queen City Printers, 1991.

45 Simeoni MC, Auquier P, Antoniotti S, Sapin C, Marco JLS: Validation of a French healthrelated quality of life instrument for adolescents: the VSP-A. Qual Life Res 2000;9:393403 .

46 Landgraf JM, Abetz L, Ware JE: Child Health Questionnaire: A User's Manual. Boston, The Health Institute, New England Medical Center, 1996.

47 Bannink EM, van Pareren YK, Theunissen NC, Raat H, Mulder PG, Hokken-Koelega AC: Quality of life in adolescents born small for gestational age: does growth hormone make a difference? Horm Res 2005;64:166174.

48 Koopman HM, Theunissen NCM, Vogels AGC, Zwinderman AH, Verloove-Vanhorick SP, Wit JM: Health-related quality of life of children with a chronic illness: parent versus child report. Gedrag Gezondheit 1999;27: 118-125.

49 Harter S: Manual for the Self-Perception Profile for Children. Denver, University of Denver, 1985.

50 VarniJW, Seid M, Rode CA: The PedsQLTM: measurement model for the pediatric quality of life inventory. Med Care 1999;37:126139. 